\title{
Current Management of Alcoholic Hepatitis and Future Therapies
}

\author{
Behnam Saberi*1 ${ }^{1}$, Alia S. Dadabhai ${ }^{1}$, Yoon-Young Jang ${ }^{2}$, Ahmet Gurakar ${ }^{1}$ and Esteban Mezey ${ }^{1}$ \\ ${ }^{1}$ Division of Gastroenterology and Hepatology, The Johns Hopkins University School of Medicine, Baltimore, MD, USA; \\ ${ }^{2}$ Department of Oncology, The Johns Hopkins University School of Medicine, Baltimore, MD, USA
}

\begin{abstract}
Alcohol is one of the most common etiologies of liver disease, and alcoholic liver disease overall is the second most common indication for liver transplantation in the United States. It encompasses a spectrum of disease, including fatty liver disease, alcoholic hepatitis ( $\mathrm{AH})$, and alcoholic cirrhosis. $\mathrm{AH}$ can range from mild to severe disease, with severe disease being defined as: Discriminant Function (DF) $\geq 32$, or Model for End-stage Liver Disease (MELD) $\geq 21$, or presence of hepatic encephalopathy. Management of the mild disease consists mainly of abstinence and supportive care. Severe $\mathrm{AH}$ is associated with significant mortality. Currently, there is no ideal medical treatment for this condition. Besides alcohol cessation, corticosteroids have been used with conflicting results and are associated with an inherent risk of infection. Overall steroids have shown short term benefit when compared to placebo, but they have no obvious long term benefits. Pentoxifylline does not improve survival in patients with severe $\mathrm{AH}$ and is no longer recommended based on the results of the STOPAH (Steroid Or Pentoxifylline for Alcoholic Hepatitis) trial. Anti-tumor necrosis factor (TNF) agents are associated with increased risk of life threatening infections and death. Currently, early stage trials are underway, mainly targeting novel pathways based on disease pathogenesis, including modulation of innate immune system, inhibition of gut-liver axis and cell death pathways, and activation of transcription factor farnesyl $X$ receptor ( $F X R)$. Future treatment may lie in human induced pluripotent stem cell (iPSC) technology, which is currently under investigation for the study of pathogenesis, drug discovery, and stem cell transplantation.
\end{abstract}

Keywords: Alcoholic hepatitis; Corticosteroids; Liver transplantation; Induced pluripotent stem cell.

Abbreviations: AASLD, American Association for the Study of Liver Disease; AH, alcoholic hepatitis; ALD, alcoholic liver disease; ALT, alanine aminotransferase; AST, aspartate aminotransferase; AUROC, area under the receiver operating characteristic; CDCA, chenodeoxycholic acid; $C I$, confidence interval; $D F$, discriminant function; FXR, farnesyl X receptor; GGT, gamma glutamyl transpeptidase; INR, international normalized ratio; iPSC, induced pluripotent stem cell; LPS, lipopolysaccharide; MELD, model end-stage liver disease; NAC, N-acetylcysteine; NAFLD, nonalcoholic fatty liver disease; NASH, nonalcoholic steatohepatitis; OPTN, Organ Procurement and Transplantation Network; OR, odds ratio; PBC, primary biliary cirrhosis; OCA, obeticholic acid; PT, prothrombin time; PTX, pentoxifylline; RR, relative risk; SBP, spontaneous bacterial peritonitis; SRTR, Scientific Registry of Transplant Recipients; STOPAH, Steroid Or Pentoxifylline for Alcoholic Hepatitis; TLR4, toll-like receptor 4; TNF tumor necrosis factor; UNOS, United Network for Organ Sharing; UTI, urinary tract infection.

Received: 21 February 2016; Revised: 27 March 2016; Accepted: 28 March 2016 DOI: $10.14218 / \mathrm{JCTH} .2016 .00006$

*Correspondence to: Behnam Saberi, Division of Gastroenterology and Hepatology, The Johns Hopkins University School of Medicine, Baltimore, MD 21287, USA Tel: +1-410-614-2543, Fax: +1-410-614-7340, E-mail: saberi.behnam@jhmi.edu
Liver transplantation has been reported with good results in highly selected patients but is controversial due to limited organ supply.

(C) 2016 The Second Affiliated Hospital of Chongqing Medical University. Published by XIA \& HE Publishing Inc. All rights reserved.

\section{Introduction}

Approximately two-thirds of the US adult population drinks alcohol each year, and $7.4 \%$ report heavy drinking and meet the criteria for alcoholism. ${ }^{1}$ However, only a minority of heavy drinkers will develop alcoholic liver disease (ALD), likely due to environmental and genetic factors. ${ }^{2}$ The economic impact of ALD is significant, with a total cost of around $\$ 185$ billion. Of this cost, $14 \%$ (around $\$ 27$ billion) is related to health care cost. ${ }^{3}$ In 2000, the mortality from ALD (reported as age-adjusted death rate) was 25 and 15 per 100,000 for Hispanics and non-Hispanics, respectively. Alcoholic cirrhosis was accounted for about $37 \%$ of liver-related deaths, which is higher than death from cirrhosis due to hepatitis $C .{ }^{4}$ ALD still remains the second most common indication for liver transplantation after hepatitis C, based on the most recent annual Organ Procurement and Transplantation Network (OPTN)/Scientific Registry of Transplant Recipients (SRTR) report. ${ }^{5}$ With new direct antiviral agents (DAAs) for treatment of hepatitis $C_{,}{ }^{6}$ ALD will be one of the leading causes of liver disease in developed countries in the near future. Therefore, there is an urgent need for new therapies for the management of ALD and more importantly alcoholic hepatitis (AH). This review focuses on the current medical and surgical management of patients with $\mathrm{AH}$ and future therapies.

\section{Spectrum of liver disease}

The clinical and pathologic spectrum of ALD ranges from alcoholic fatty liver disease (alcoholic steatosis) to cirrhosis with various survival rates. ALD can be divided into: alcohol induced steatosis (microvesicular, macrovesicular), alcoholic hepatitis and alcoholic cirrhosis. There is usually overlap of different pathological findings in a given patient. ${ }^{2,7}$

\section{Alcoholic fatty liver}

Alcohol induced fatty liver is the earliest and most common presentation of ALD which develops in more than $80 \%$ of heavy drinkers. ${ }^{8}$ This condition should be differentiated from nonalcoholic fatty liver disease (NAFLD), which is associated 
with metabolic syndrome. ALD and NAFLD have a similar pathologic spectrum, and they have been described to coexist in the clinical setting. ${ }^{9,10}$ Alcohol induced fatty liver disease is usually asymptomatic and may completely resolve after 2-6 weeks of alcohol abstinence. ${ }^{2,11}$ Weight loss by low calorie diet in conjunction with increase physical activity reduces hepatic steatosis in patients with NAFLD. ${ }^{12}$

\section{Alcoholic cirrhosis}

In those patients who continue to drink, the risk of developing cirrhosis will increase to about $30 \% .{ }^{13}$ There is an increased risk of developing cirrhosis with ingestion of $60-80 \mathrm{~g} /$ day of alcohol for 10 years or longer in men and $20 \mathrm{~g} /$ day for women; however, only $6 \%-41 \%$ of those drinking this amount of alcohol will develop cirrhosis. ${ }^{1}$ Alcoholic cirrhosis has a high mortality rate, with a worldwide reported mortality rate of $38 \%-50 \%$ of all cirrhosis-related death. The long-term prognosis of alcoholic cirrhosis is dependent on alcohol abstinence. ${ }^{1,14}$

\section{Alcoholic hepatitis $(\mathrm{AH})$}

Superimposed episodes of AH may occur in patients with ALD that could range from mild to severe and life threatening episodes. The true prevalence of $\mathrm{AH}$ is not known, but studies evaluating the histology of patients with ALD suggest that $\mathrm{AH}$ might be present in about $10 \%-35 \%$ of alcoholic patients. ${ }^{15,16}$ Severe $\mathrm{AH}$ is not a benign disease and has a reported 28 day mortality as high as $50 \%$ without treatment. ${ }^{17,18}$ More than half of the patients with $\mathrm{AH}$ might have cirrhosis at the time of liver biopsy or will develop cirrhosis during the course. ${ }^{2,19}$ When evaluating survival in patients with $\mathrm{AH}$, it is important to distinguish the patients who have concomitant cirrhosis. Even if the AH component is treated, the cirrhosis might not reverse, and the risk of death from complications of portal hypertension and cirrhosis remains.

\section{Other variants of ALD}

Other forms of ALD have been reported in the literature. Foamy fatty degeneration was reported in 21 heavy drinkers, presenting mainly with jaundice and hepatomegaly. The laboratory findings were significant for marked elevation of serum aminotransferases, more prolonged elevation of alkaline phosphatase and bilirubin, and elevated cholesterol with no leukocytosis when compared to patients with $\mathrm{AH}$. The liver pathology was consistent with mainly foamy fatty change (microvesicular fat) and megamitochondria. Foamy fatty degeneration has been reported to have a good prognosis with rapid recovery in all patients with alcohol abstinence. ${ }^{20,21}$ Another variant of ALD is Zieve syndrome, first described in 1957, which was defined as a triad of jaundice, hyperlipidemia, and transient hemolytic anemia in patients with alcoholic steatohepatitis. ${ }^{22}$

\section{Diagnosis of $\mathrm{AH}$}

For diagnosis of $\mathrm{AH}$, a detailed history, including the history of alcohol intake, and physical examination is critical. On examination, apart from signs of portal hypertension and jaundice, patients with $\mathrm{AH}$ might have fever in the absence of infection. Hepatic bruit may be present in more than half of the patients. ${ }^{15,23}$ Laboratory findings are typical for aspartate aminotransferase (AST) and alanine aminotransferase (ALT) elevation usually less than $300 \mathrm{U} / \mathrm{L}$ with a ratio of $>2 / 1.24,25$ However, in patients with foamy fatty degeneration, higher AST levels have been reported. ${ }^{20}$ Patients with $\mathrm{AH}$ usually have high bilirubin and an increase in prothrombin time (PT)/international normalized ratio (INR). Leukocytosis in the absence of infection can be seen in patients with $A H$, but the absence of leukocytosis does not rule out the diagnosis. ${ }^{26,27}$

Diagnosis of different forms of ALD based only on clinical presentation and laboratory findings is difficult. ${ }^{28}$ Another challenge is that different types of ALD can develop concomitantly. As mentioned earlier, more than half of the patients with $\mathrm{AH}$ may have alcoholic cirrhosis as well. ${ }^{2}$ Liver biopsy remains the gold standard for diagnosis of $\mathrm{AH}$; however, the indication for liver biopsy remains controversial. ${ }^{28}$ In some centers, transjugular liver biopsy is performed to confirm the diagnosis of $\mathrm{AH}$ when the diagnosis remains uncertain, despite reviewing the clinical and laboratory data especially, and when corticosteroid with its potential side effects is being considered for treatment. ${ }^{29}$ In some studies, hepatocellular damage (hepatocellular ballooning, presence of Mallory bodies), inflammatory infiltrate (mainly polymorphonuclears), and pericellular fibrosis have been used for diagnosis of $\mathrm{AH} .{ }^{15,30-32}$

\section{Treatment}

\section{Alcoholic abstinence and supportive care}

Alcohol abstinence is the most important predictor for determining long-term survival in patients with $\mathrm{AH}$. In the study by Potts et al., 5 year survival was significantly higher in $\mathrm{AH}$ patients who remained abstinent compared to those $\mathrm{AH}$ patients who relapsed or continued to drink ( $75 \%$ vs. $27 \%$ and $21 \%$, respectively, $p=0.005) .{ }^{33}$ Nutritional support and management of complications of portal hypertension are other important factors in the care of patients with $\mathrm{AH}$.

\section{Nutrition}

Malnutrition as well as obesity in alcoholic patients are wellrecognized phenomena that can critically impact the development and progression of liver disease. ${ }^{34-36}$ The degree of malnutrition is correlated closely with the development of all the serious complications of liver disease (e.g., ascites, encephalopathy, and hepatorenal syndrome) as well as the overall mortality. ${ }^{37}$ The etiology of nutritional deficiencies in alcoholics is multifactorial and include: decreased caloric intake, inadequate consumption of nutrients, impaired metabolism of vitamins due to possibly concomitant chronic pancreatitis, disruption of the gut microbiome and mucosal integrity, gastritis, and diarrhea/vomiting. ${ }^{38-41}$ Overall, patients who are not meeting their nutritional needs by oral diet should receive supplementation. An enteral route is preferred whenever possible, as it maintains the gut mucosal integrity and prevents bacterial translocation. ${ }^{42}$ Despite improvement in nutritional parameters and liver tests in most studies, only a few studies have shown survival benefit with nutritional supplementation, and the majority of studies have not demonstrated a change in mortality. ${ }^{39,41}$ In review of five randomized clinical trials evaluating alimentary augmentation, no survival benefit was noted in the supplemented group ( $17 \%-35 \%$ mortality) compared to 
the controlled group ( $16 \%-39 \%$ mortality)..$^{42}$ In a randomized control trial of vitamin $E$ vs. placebo in patients with $A H$, vitamin $\mathrm{E}$ improved serum hyaluronic acid but had no beneficial effect on liver function and survival. ${ }^{43}$

\section{Medical management}

\section{Corticosteroids}

Corticosteroids are the current main treatment for severe $\mathrm{AH}$ (defined as $\mathrm{DF} \geq 32$, or MELD $\geq 21$, or presence of hepatic encephalopathy) in patients who do not have any contraindications for steroid treatment. ${ }^{44,45}$ Corticosteroids work by changing the balance of cytokines, reducing proinflammatory cytokines such as tumor necrosis factor (TNF) $-\alpha$, and increasing anti-inflammatory cytokines such as interleukin 10.46 Data from clinical trials and metaanalyses of corticosteroids have been conflicting. ${ }^{47-52} \mathrm{~A}$ recent Cochrane meta-analysis concluded that, overall, there is no clear evidence that steroids are effective in the management of $\mathrm{AH}$. However, this meta-analysis concluded that glucocorticosteroids did significantly reduce mortality in the subgroup of trials with patients with a Maddrey score of 32 or higher or in patients who had hepatic encephalopathy. In addition, this study showed that steroids reduced mortality in low bias-risk studies. The potential for bias was due to heterogeneity of data. ${ }^{53,54}$ To overcome this issue, Mathurin et al. analyzed individual data from five randomized controlled trials and showed that steroids have survival advantage for severe $\mathrm{AH}$ (defined as $\mathrm{DF} \geq 32$ or hepatic encephalopathy), with a 28 day survival of $85 \%$ among treated patients compared to $65 \%$ for patients receiving placebo $(p=0.001){ }^{45}$ Prednisolone $40 \mathrm{mg}$ for a total of 4 weeks (28 days) or other regimens have been used in the trials. Prednisolone is preferred (but not demonstrated to be better) over prednisone, as the latter requires conversion within the liver to its active form, prednisolone. ${ }^{54}$

\section{Contraindications for steroids}

The main contraindications for steroid treatment in patients with $\mathrm{AH}$ are renal failure, active gastrointestinal bleeding, uncontrolled hyperglycemia, acute pancreatitis, psychosis, and infection. ${ }^{54}$ Here, we discuss infection as a contraindication for steroid therapy.

Infections are common and could be fatal in patients with $\mathrm{AH} .{ }^{55}$ Around $25 \%$ of patients with severe $\mathrm{AH}$ have some form of infection at the time of presentation. ${ }^{56}$ Infection was considered an absolute contraindication for steroid therapy, but recently the position on this matter has changed. ${ }^{57}$ In the study by Louvet et al., in a group of patients with severe $\mathrm{AH}$ the most common infections at the time of presentations were: spontaneous bacterial peritonitis (SBP) 44\%, urinary tract infections (UTI) $37 \%$, respiratory infections $13 \%$, and others including skin infections in $11 \%$. The 2 -month survival of patients infected and treated before initiation of steroids was similar to that of patients not infected before steroids. In the follow-up, infection developed in $24 \%$ of patients. The pattern of infections after steroid treatment was different for those patients who had infection prior to steroid therapy. The most common infections were pulmonary $40.3 \%$, followed by SBP or bacteremia $28.1 \%$, UTI $17.5 \%$, and other infections $14.1 \%$. Patients infected after corticosteroids had a significantly lower 2-month survival than patients with no infection ( $46.4+/-6.9 \%$ vs. $77.5+/-3.2 \%, p<0.00001)$. Therefore, it is very important to differentiate infection on admission from infection that occurs after initiation of steroids, as survival rates are completely different. Overall, infection was more common in steroid null responders than responders. In multivariate analysis, only Lille model and MELD score were independently associated with survival, whereas infection was not. This study suggested that the development of infection after steroid therapy is most likely secondary to absence of improvement of liver function; however, the study could not rule out the possibility that steroids contributed to infection susceptibility. ${ }^{56}$ In a recent meta-analysis of clinical trials, the group of patients that received steroids had a higher overall incidence of infection than the control group. ${ }^{53}$

\section{Response to steroids}

\section{Lille score}

Lille score was primarily described to assess the steroid response in patients with severe $\mathrm{AH}$ after 7 days of treatment. A total of 295 patients with biopsy proven, severe $A H$ (DF $\geq 32$ or hepatic encephalopathy) treated with steroids on admission with an overall 6-month survival of $65.4+/-2.9$ were evaluated in a cohort of patients. In univariate analysis, the prognostic values of clinical and biological variables predicting 6-month survival were studied. Ten variables reached statistical significance. Subsequent multivariate analysis of six objective variables using logistic regression was calculated as Lille score, ranging from 0 to 1 . Lille score $=[3.19-0.101 *$ (age in years $)+0.147 *$ (albumin day 0 in $\mathrm{g} / \mathrm{L})+0.0165 *$ (evolution in bilirubin level in $\mu \mathrm{M})-0.206 *$ (renal insufficiency) $-0.0065 *$ (bilirubin day 0 in $\mu M$ ) $-0.0096 *$ (prothrombin time in seconds)]. The area under the receiver operating characteristic (AUROC) curve of the Lille model was $0.89+/-0.02$, which was validated and shown to be superior than Child-Pugh score, Maddrey score, MELD score, and Glasgow scores for prediction of 6-month survival. Patients above the ideal cutoff of 0.45 showed a marked decrease in 6-month survival compared with those below the cutoff $(25 \%+/-3.8 \%$ versus $85 \%+/-2.5 \%$, $p<0.0001)$. This cutoff was able to identify approximately $75 \%$ of the observed deaths, and was suggested for early identification and management of subjects with substantial risk of death who would not respond to steroid therapy according to the Lille model. ${ }^{58}$ In a follow-up study with individual analysis of five randomized trials, patients were classified into three groups according to their percentile distribution of Lille score and survival analysis: complete responders (Lille score $\leq 0.16$; $\leq 35$ th percentile), partial responders (Lille score $0.16-0.56$; 35th-70th percentile), and null responders (Lille $\geq$ 0.56 ; $\geq 70$ th percentile). Twenty-eight-day survival was strongly associated with these groupings ( $91.1+/-2.7 \%$ vs. $79.4+/-3.8 \%$ vs. $53.3+/-5.1 \%$, respectively, $p<0.0001$ ). Overall, these studies show that steroid therapy is beneficial mainly in complete responders and partial responders but not in null responders. Therefore, steroids should not be continued beyond 7 days in null responders based on their Lille score, as there will be no survival benefit in this population and the use of corticosteroids, in general, are not without risks. ${ }^{45}$ 
Saberi B. et al: Management of alcoholic hepatitis

\section{Pentoxifylline}

Pentoxifylline (PTX) is a phosphodiesterase inhibitor and a possible TNF- $\alpha$ inhibitor. ${ }^{54,59}$ The first pilot study with PTX was conducted in 1991 by McHutchison et al. in patients with severe AH (DF score $\geq 32$ ), and they showed that PTX could reduce the development of hepatorenal syndrome and mortality compared to those receiving placebo. ${ }^{60,61}$ Subsequently, a study was conducted from Rancho Los Amigos California in 2000 by Akriviadis et al. in 101 patients with severe $\mathrm{AH}$ in a 4 week double-blind randomized trial (PTX $400 \mathrm{mg}$ orally, three times daily) compared to placebo. The study confirmed that treatment with PTX improves short-term survival in patients with $\mathrm{AH}$, and the benefit was attributed to a decrease in the risk of developing hepatorenal syndrome. ${ }^{62}$

The American Association for the Study of Liver Disease (AASLD) guidelines recommend the use of PTX for severe $\mathrm{AH}$ if there are contraindications to corticosteroids. ${ }^{2,63}$ A few trials have evaluated the efficacy of PTX in the management of $\mathrm{AH}$ in comparison to placebo. Recent meta-analysis of four clinical trials, three in abstract and one in paper format, showed a reduced incidence of fatal hepatorenal syndrome with PTX when compared to placebo (relative risk (RR): 0.47 , $0.26-0.86, p<0.01$ ) but no survival benefit at 1 month (RR: $0.58,0.31-1.07, p=0.06) .{ }^{63-67}$ In the recent study STOPAH (Steroid Or Pentoxifylline for Alcoholic Hepatitis) trial that will be discussed, PTX had no impact on survival compared to placebo in the treatment of severe $\mathrm{AH} .{ }^{68}$

\section{PTX vs. Corticosteroids}

In the meta-analysis of three trials that compared the efficacy of PTX vs. prednisolone in severe $\mathrm{AH}$, two as papers and one as an interim report, there were no significant differences between treatment groups. ${ }^{63,69-71}$ In a recent multicenter randomized noninferiority trial comparing PTX vs. prednisolone, the authors concluded that the efficacy of PTX is not statistically equivalent to the efficacy of prednisolone, supporting prednisolone as a preferred option. ${ }^{72}$

Although it has been difficult to confirm the superiority of PTX or corticosteroids in the treatment of severe $\mathrm{AH}$ in a sufficiently large population, ${ }^{73}$ this was recently studied in the STOPAH trial in more than thousand patients. In this multicenter double blinded randomized trial, $2 \times 2$ factorials were designed to study the benefit of both prednisolone $40 \mathrm{mg}$ and/or PTX $400 \mathrm{mg}$ TID for 4 weeks. In total, 1,103 patients with a clinical diagnosis of severe $A H(D F \geq 32)$ were randomized into four arms: A. Placebo/Placebo; B. Prednisolone/Placebo; C. PTX/Placebo; D. PTX/Prednisolone. At 28 days, the percentage of death in the arms were 17, 14, 19, and 13 , respectively. Prednisolone reduced the risk of 28-day mortality, but this benefit was not sustained at 3 months and 1 year. As expected, infection was more common in the prednisolone group $(13 \%)$ than in the no prednisolone group $(7 \%)(p=0.002)$. This study clearly shows that PTX has no impact on disease progression and should no longer be used for treatment of severe $\mathrm{AH} .{ }^{68,74}$ It is worth mentioning that transjugular liver biopsy was not a requirement for enrolling patients in the trial. ${ }^{74}$
Combination therapy (PTX plus corticosteroids) vs. corticosteroid monotherapy

In a multicenter randomized control trial of 270 patients with severe $\mathrm{AH}$, there was no statistical difference in 6-month survival between 4 weeks of dual therapy with prednisolone and PTX vs. prednisolone monotherapy. The study was underpowered to detect a significant difference in hepatorenal syndrome between the two groups. ${ }^{75}$ The analysis of pooled data from three clinical trials did not show survival benefit from PTX and steroid combination therapy when compared to steroid monotherapy. ${ }^{63}$ PTX was also studied as a salvage option in steroid null responders, but there was no benefit. ${ }^{29,76}$ These findings were confirmed in the multicenter European STOPAH trial, as discussed previously. Taken together, this data demonstrates that there is no therapeutic benefit of dual therapy in comparison with steroid monotherapy in the management of patients with severe AH. ${ }^{66}$

\section{Anti-TNFs}

Experimental and clinical evidence has shown that TNF- $\alpha$ is a major contributor to the pathogenesis of $\mathrm{AH}$, and elevated TNF- $\alpha$ is a major predictor of decreased long-term survival in these patients. ${ }^{77,78}$ The role of Infliximab and etanercept have been studied in the treatment of $\mathrm{AH}$ and will be discussed here.

\section{Etanercept}

In a multicenter study by Boetticher et al., 48 patients with severe $\mathrm{AH}$ were randomized to receive either etanercept (TNF- $\alpha$ neutralizing molecule) or placebo for 3 weeks. The results showed similar 1 -month mortality $(22.7 \%$ vs. $36.4 \%$, odds ratio (OR) 1.8; 95\% confidence interval (CI), 0.5-6.5). The 6-month mortality was significantly higher in the etanercept group than in the placebo group (57.7\% vs $22.7 \%$, $\mathrm{OR}, 4.6 ; 95 \% \mathrm{CI}, 1.3-16.4 ; p=0.17)$. The rate of infectious serious adverse events were significantly higher in the etanercept group than the placebo group (34.6\% vs. $9.1 \%$, $p=0.04)$, suggesting that the increase in late mortality in patients receiving etanercept was related to impaired liver regeneration or suppression of the immune system by etanercept. ${ }^{79}$

\section{Infliximab}

In a multicenter study by Naveau et al., 36 patients with severe $\mathrm{AH}$ were randomized to receive intravenous infliximab (10 mg/kg) in weeks 0,2 , and 4 or placebo. All patients received prednisolone $40 \mathrm{mg} /$ day for 4 weeks. The probability of death at 2 months was higher in patients who received infliximab than in those who received placebo, but the difference was not statistically significant. This study had to be stopped early by the follow-up committee and the sponsor. The frequency of severe infection within 2 months was significantly higher in the group that received infliximab than that in the placebo group and was thought to be related to significantly lower stimulation capacity of neutrophils. ${ }^{80}$ 


\section{N-acetylcysteine (NAC)}

A study evaluating combination therapy with prednisolone plus NAC in comparison to prednisolone monotherapy showed a significant decrease in mortality with combination therapy at 1 month ( $8 \%$ vs. $24 \%, p=0.006$ ) but not at 6 months ( $27 \%$ vs. $38 \%, p=0.07)$. Death due to hepatorenal syndrome was less frequent in the combination group than in the steroid monotherapy group at 6 months ( $9 \%$ vs. $22 \%, p=0.02$ ). Infections were also less frequent in the prednisolone-NAC group compared to prednisolone only group. ${ }^{31}$ At this time, it is not clear if dual therapy with steroid and NAC should become the standard of care in the management of patients with $\mathrm{AH}$ as opposed to steroid alone. ${ }^{81}$

\section{Liver transplantation}

Although liver transplant represents the definite treatment for patients with decompensated alcoholic cirrhosis, it remains an ethically controversial option for the management of patients with $A L D$, including $A H .{ }^{82,83}$ The main controversy is based on the public opinion that ALD is self-inflicted and given the high demand for limited organs, the allocation should be made to patients who "deserve the liver transplant". ${ }^{84-86}$ The other concern is the risk of recidivism. ${ }^{87}$ Most transplant centers use the 6-month abstinence rule to achieve two goals: first, this will allow time for the liver to recover from the hepatitis due to recent alcohol exposure by abstinence and medical treatment; and second, the patient's commitment to sobriety can be assessed during this time, based on the rationale that duration of abstinence prior to transplant might predict abstinence after liver transplantation. ${ }^{83,88,89}$ Nevertheless, the 6 -month rule requirement usually is not met by most patients with severe AH that are null responders to steroids since these patients usually have a recent history of alcohol use. Furthermore, pretransplant abstinence does not necessarily predict recidivism after liver transplant. ${ }^{84,85,90}$ The other argument against the 6-month rule for liver transplant in patients with severe $A H$ is the high mortality in Lille null responders within this time period. Mathurin et al. found that $75 \%$ of patients with severe AH who were not responsive to steroids who did not undergo liver transplant died within the 6-month follow-up period. ${ }^{91}$

Another approach introduced recently is to proceed with early liver transplant in patients with severe AH. Liver transplant was performed in 26 patients with severe $\mathrm{AH}$ who were null responders to steroid treatment, and outcomes were compared to matched controls. These patients were highly selected based on a thorough psychosocial evaluation and included only $2 \%$ of total patients that presented with severe $\mathrm{AH}$. The selection criteria included a lack of response to medical therapy, severe $\mathrm{AH}$ as the first liver decompensating event, strong family support, absence of a coexisting severe psychiatric disorder, and agreement by the patient to adhere to lifelong total alcohol abstinence. The transplant had to be approved by the liver transplant group. The centers used only $2.9 \%$ of available grafts for this indication for liver transplant. The patients with $\mathrm{AH}$ who received early liver transplant had a significantly higher cumulative 6-month survival than patients who were not transplanted $(77.8+/-8 \%$ vs. $23+/-8 \%$ respectively, $p<0.001)$, with benefit remaining through 2 years of follow-up. Only three patients resumed alcohol drinking at 720,740 , and 1,140 days after transplantation, and only one reported harmful drinking. There was no graft loss due to alcohol in the study. ${ }^{91}$

Short- and long-term outcomes of liver transplant in patients with severe $\mathrm{AH}$ were reported by Singal et al. using the United Network for Organ Sharing (UNOS) database. Fifty-five patients that were transplanted for $\mathrm{AH}$ were compared with 165 matched patients transplanted for alcoholic cirrhosis, and 1,3 , and 5 year graft survival was $87 \%$, $82 \%$, and $75 \%$, respectively, and 1,3 , and 5 year patient survival was $93 \%, 87 \%$, and $80 \%$, respectively. ${ }^{92}$ Recidivism after liver transplant is very variable. Twelve percent to $49 \%$ of patients with ALD will restart some amount of drinking and $10 \%-15 \%$ of patients will resume heavy drinking. However, the risk of graft loss due to recidivism is only $0 \%-5 \%$ in $\mathrm{AH}$ patients receiving a liver transplant, but is reported to be higher in some series. Overall, harmful drinking in the post-transplant period can affect the long-term transplant outcomes, mainly due to poor compliance with immunosuppressive medications and alcohol induced liver injury. ${ }^{93-95}$

In summary, early liver transplant is effective in the management of patients with severe $\mathrm{AH}$ who failed steroid treatment. Patient selection remains extremely controversial and needs to be further determined. The patients should be selected based on strict criteria, and it should be emphasized that patients with severe $\mathrm{AH}$ who do not respond to steroids have a very short-term mortality rate without liver transplantation. ${ }^{91}$

\section{Future Therapies}

As discussed in this review (summarized in Fig. 1), the medical management of $\mathrm{AH}$ patients at this time is limited to steroids. Use of corticosteroids can be associated with significant risk, such as infection, especially in this sick population of patients. In addition, the long-term benefit of steroids is still not established. Recent data suggest that PTX lacks efficacy and is no longer recommended (STOPAH trial). ${ }^{68}$

Therefore, effective new pharmacologic therapies with more favorable side effect profiles are greatly needed for the treatment of $\mathrm{AH}$ patients. One of the challenges of drug discovery in the field is the lack of ideal animal models that entirely mimic human disease. ${ }^{96}$ Multiple new clinical trials are underway with novel therapeutic targets based on essential pathways involved in the pathogenesis of $\mathrm{AH}$. This subject was reviewed in few reviews and at a recent AASLD meeting. Here, we will briefly discuss some of the most important therapeutic targets. Alcohol disrupts the intestinal epithelial barrier, resulting in increased gut permeability to microbiota. The bacterial endotoxin lipopolysaccharide (LPS) increases in portal circulation and activates toll-like receptor 4 (TLR4), leading to activation of the innate immune system and release of various cytokines. Blockage of these pathways could have therapeutic implications for the treatment of $\mathrm{AH} \cdot{ }^{16,29,97}$

\section{Gut-Liver Axis}

Disruption of the intestinal epithelial barrier results in increased gut permeability, and has been suggested as an essential pathway in the pathophysiology of AH.97,98 Probiotics have been used in the management of ALD. Short-term use of VSL\#3 in alcoholic cirrhosis patients was shown to decrease markers of oxidative stress and plasma cytokines 
Saberi B. et al: Management of alcoholic hepatitis

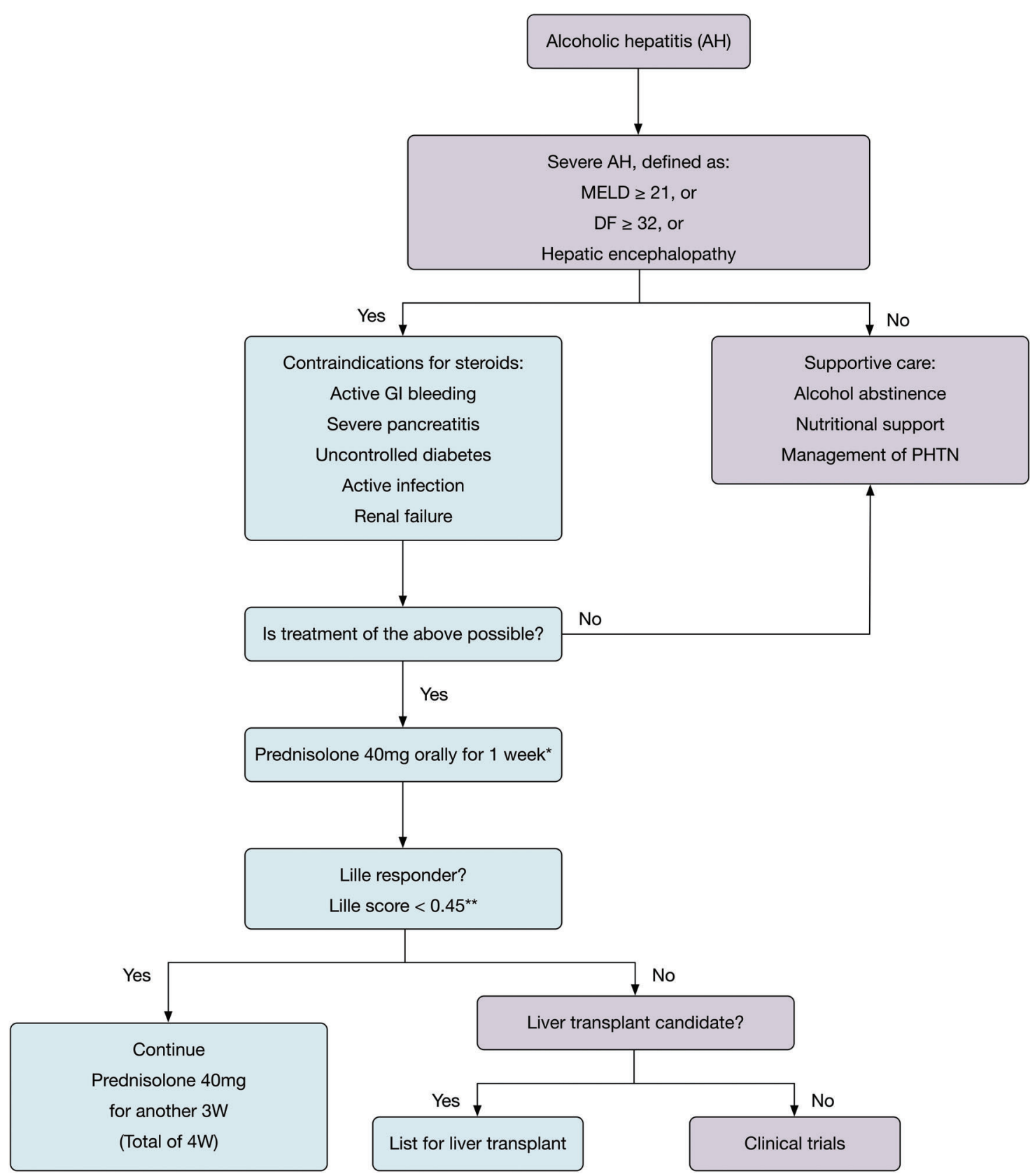

Fig. 1. Proposed algorithm for management of patients with alcoholic hepatitis.

* Note that pentoxifylline is not included in this algorithm. Based on recent STOPAH trial, ${ }^{68}$ it was shown that pentoxifylline had no impact on disease progression and is no longer recommended for the treatment of severe alcoholic hepatitis.

** In a separate analysis, patients were classified into three groups based on their Lille score and survival, and cutoff of 0.56 determined nonresponse: complete responders (Lille score $\leq 0.16 ; \leq 35$ th percentile), partial responders (Lille score $0.16-0.56 ; 35$ th-70th percentile) and null responders (Lille $\geq 0.56 ; \geq 70$ th percentile). 45

Abbreviations: AH, alcoholic hepatitis; DF, discriminant function; GI, gastrointestinal; MELD, Model for End-stage Liver Disease; PHTN, portal hypertension; w, week(s).

(TNF- $\alpha$, IL-6, and IL-8). ${ }^{99}$ Kirpich et al. conducted a prospective, randomized, clinical trial to study the effects of alcohol and probiotics on the bowel flora and alcohol-induced liver injury on 66 hospitalized patients. Patients were randomized to receive 5 days of Bifidobacterium bifidum and Lactobacillus plantarum 8PA3 versus standard therapy alone, abstinence plus vitamins. After 5 days of probiotic therapy in alcoholic patients, those who were treated with probiotics had significantly lower AST, ALT, gamma glutamyl-transpeptidase (GGT), and total bilirubin levels than those treated with standard therapy alone. ${ }^{100}$ Currently there are ongoing clinical trials evaluating the effect ciprofloxacin, amoxicillin clavulanate, Lactobacillus rhamnosus, zinc, and rifaximin in the management of patients with $\mathrm{AH} .{ }^{101}$ 


\section{Innate immune system}

Activation of the innate immune system is one of the main steps in the development of $\mathrm{AH}$. Activation of kupffer cells causes release of IL-1 $\beta$, a potent pro-inflammatory cytokine. IL1 $\beta$ binds to its receptor IL-1R1, which leads to the recruitment of other inflammatory cells. ${ }^{102,103}$ It was shown recently that an IL1 $\beta$ receptor antagonist was protective against alcoholic liver injury in an animal model. ${ }^{103}$ Use of the IL1 $\beta$ receptor antagonist Anakinra in combination with PTX and zinc is currently being tested in the management of $\mathrm{AH} .{ }^{101}$

Another key cytokine, IL-22, was suggested alone or in combination with steroids to be a potential therapeutic option to ameliorate ALD, due to its multiple beneficial properties, including its antioxidant, antiapoptotic, antisteatotic, antimicrobial, and proliferative properties. Therefore, IL-22 might be useful in treating patients with $\mathrm{AH}$. Additionally, side effects due to IL22 may be minimal, as IL-22R expression is restricted expression to epithelial cells, such as hepatocytes. ${ }^{104}$

\section{Apoptosis Pathways}

Apoptosis is a prominent feature in the pathophysiology of $\mathrm{AH} .{ }^{105}$ Excessive hepatocyte apoptosis stimulates inflammation and results in the production of proinflammatory cytokines and reactive oxygen species by the innate immune system. ${ }^{106}$ Therefore, inhibition of apoptosis with different caspase inhibitors can be therapeutic in patients with $\mathrm{AH}$. The caspase inhibitor GS-9450 was shown to be effective in the treatment of patients with nonalcoholic steatohepatitis (NASH). ${ }^{107}$ The effectiveness of a pancaspase inhibitor compared to placebo is currently being evaluated in patients with severe $\mathrm{AH}$ who have contraindication to steroids. ${ }^{29}$

\section{Farnesoid $X$ receptor (FXR)}

FXR is a nuclear receptor for bile acids, and its activation has been shown to be essential in the treatment of primary biliary cirrhosis (PBC). ${ }^{108,109}$ Obeticholic acid (OCA) is a semisynthetic analogue of the primary bile acid chenodeoxycholic acid (CDCA), which selectively activates FXR. ${ }^{110}$ In the FLINT trial, treatment with OCA improved insulin resistance and liver histology in patients with NASH. A phase II clinical trial of OCA in AH is currently underway. ${ }^{108}$

\section{Potential of human induced pluripotent stem cell (iPSC) based therapy for ALD}

Challenges remain for developing therapeutic approaches targeting ALD, including $\mathrm{AH}$, partly because of the lack of human-relevant model systems to study the effect of alcohol on the liver. ${ }^{111}$ In recent years, human iPSCs have been generated from diverse human somatic cells, $112-117$ and these cells can then be differentiated into a spectrum of mature human cell types, including functional hepatocytes. ${ }^{112-114,116,118-123}$ This development has enabled us to access an unlimited supply of hepatocytes, which was one of the major challenges in the past. Moreover, human iPSCs retain the same genetic information of the donor (i.e., patient) tissues, making iPSCs a promising resource to study human diseases. ${ }^{12,113,116,117,120}$ Human iPSC lines from healthy donors and multiple liver disease patients have been established. ${ }^{112-114,119}$ Using step-wise hepatic differentiation protocols, these iPSCs can be induced to definite endoderm, hepatic progenitor cells, and mature hepatocyte-like cells under defined conditions. ${ }^{112-114,116}$ The two main uses of human iPSC technology for liver diseases are drug discovery and cell transplantation. ${ }^{122}$ Using iPSCs for drug development, would require establishing patient iPSC-based disease models for testing potential drugs. The human iPSC-hepatic differentiation technology has allowed us to establish effective largescale drug screening and drug discovery studies using an iPSC-based liver disease model, which is critical for translating the iPSC technology into novel therapies for untreatable liver diseases. ${ }^{116}$ More recently, it was observed that exposure to ethanol at the pathophysiological dosage induced apoptosis during differentiation of human iPSC-derived endoderm cells into hepatic progenitor cells and significantly reduced proliferative activity of mature stage hepatic cells. ${ }^{123}$ Importantly, increased amounts of lipid droplets were detected in ethanoltreated iPSC-derived hepatocytes compared to controls, indicating the possibility of modeling ALD using human iPSCs.

Pathogenesis research using patient-relevant iPSC models of $\mathrm{AH}$ will aid in the discovery of better cellular and molecular targets for drug development. Regenerative therapy using iPSCs will require in vivo functional testing of these cells. Perhaps a more immediate use of human iPSC-derived cells is the in vitro screening of candidate drugs, as improving and evaluating the in vivo function for most iPSC-derived cell types is still in the future. Although there are many technical hurdles to overcome before establishing iPSC-based tailored therapy for ALD patients, the potential of pluripotent stem cell therapy is great. Together with continued improvements in current therapies, iPSC technology provides an additional new therapy, but much more work needs to be done to demonstrate their true value in the clinic.

\section{Conclusions}

ALD remains one of the leading causes of liver disease in the United States. The clinical and pathological spectrum of disease includes alcoholic fatty liver, alcoholic hepatitis and alcoholic cirrhosis. In general, diagnosis of AH solely based on clinical and laboratory data might be challenging, as there is significant overlap between various forms of ALD. Liver biopsy remains the gold standard when the diagnosis is unclear, especially when steroids are being considered. The most important predictor for determining long-term survival in $\mathrm{AH}$ patients is alcohol abstinence. Steroids have some short term benefit in treatment of severe $\mathrm{AH}$, but long term effect is unclear. Overall, PTX does not improve outcomes in patients with severe $\mathrm{AH}$. Liver transplant has shown good results in the management of $\mathrm{AH}$ patients who have failed medical therapy, however patient selection remains a major challenge. There are multiple ongoing clinical trials targeting novel pathways involved in the pathogenesis of $\mathrm{AH}$. Human iPSCs are currently being used as a novel technology for studying the pathogenesis of ALD with potential for drug discovery.

\section{Conflict of interest}

None

\section{Author contributions}

Designing the manuscript, collecting the data, drafting the article and reading and approving the final draft of the 
manuscript (BS), designing the manuscript, collecting the data, drafting the article and reading and approving the final draft of the manuscript (AD), designing the manuscript, collecting the data, drafting the article and reading and approving the final draft of the manuscript (YYJ), designing the manuscript, drafting the article and reading and approving the final draft of the manuscript. In addition contributed by revisiting the article for intellectual content (AG), designing the manuscript, drafting the article and reading and approving the final draft of the manuscript, revisiting the article for intellectual content (EM).

\section{References}

[1] Mandayam S, Jamal MM, Morgan TR. Epidemiology of alcoholic liver disease. Semin Liver Dis 2004;24:217-232. doi: 10.1055/s-2004-832936

[2] O'Shea RS, Dasarathy S, McCullough AJ, Practice Guideline Committee of the American Association for the Study of Liver D, Practice Parameters Committee of the American College of G. Alcoholic liver disease. Hepatology 2010;51:307-328. doi: 10.1002/hep.23258

[3] Kim WR, Brown RS Jr, Terrault NA, El-Serag H. Burden of liver disease in the United States: summary of a workshop. Hepatology 2002;36:227-242. doi: 10.1053/jhep.2002.34734

[4] Yoon YH, Yi HY, Thomson PC. Alcohol-related and viral hepatitis C-related cirrhosis mortality among Hispanic subgroups in the United States, 2000-2004. Alcohol Clin Exp Res 2011;35:240-249. doi: 10.1111/j.15300277.2010.01340.x

[5] Kim WR, Smith JM, Skeans MA, Schladt DP, Schnitzler MA, Edwards EB, et al. OPTN/SRTR 2012 Annual Data Report: liver. Am J Transplant 2014;14 Suppl 1:69-96. doi: 10.1111/ajt.12581

[6] Curry MP, Forns X, Chung RT, Terrault NA, Brown R, Jr, Fenkel JM, et al. Sofosbuvir and ribavirin prevent recurrence of $\mathrm{HCV}$ infection after liver transplantation: an open-label study. Gastroenterology 2015;148:100-107. e101. doi: 10.1053/j.gastro.2014.09.023

[7] Lefkowitch JH. Morphology of alcoholic liver disease. Clin Liver Dis 2005;9: 37-53. doi: 10.1016/j.cld.2004.11.001

[8] Harrison DJ, Burt AD. Pathology of alcoholic liver disease. Baillieres Clin Gastroenterol 1993;7:641-662. doi: 10.1016/0950-3528(93)90006-E

[9] Toshikuni N, Tsutsumi M, Arisawa T. Clinical differences between alcoholic liver disease and nonalcoholic fatty liver disease. World J Gastroenterol 2014:20:8393-8406. doi: 10.3748/wjg.v20.i26.8393

[10] Brunt EM, Tiniakos DG. Histopathology of nonalcoholic fatty liver disease. World J Gastroenterol 2010;16:5286-5296. doi: 10.3748/wjg.v16.i42. 5286

[11] DiehI AM. Alcoholic liver disease: natural history. Liver Transpl Surg 1997;3: 206-211. doi: 10.1002//t.500030303

[12] Chalasani N, Younossi Z, Lavine JE, Diehl AM, Brunt EM, Cusi K, et al. The diagnosis and management of non-alcoholic fatty liver disease: practice guideline by the American Gastroenterological Association, American Association for the Study of Liver Diseases, and American College of Gastroenterology. Gastroenterology 2012;142:1592-1609. doi: 10.1053/j.gastro. 2012.04.001

[13] Teli MR, Day CP, Burt AD, Bennett MK, James OF. Determinants of progression to cirrhosis or fibrosis in pure alcoholic fatty liver. Lancet 1995;346: 987-990. doi: 10.1016/S0140-6736(95)91685-7

[14] Stinson FS, Grant BF, Dufour MC. The critical dimension of ethnicity in liver cirrhosis mortality statistics. Alcohol Clin Exp Res 2001;25:1181-1187. doi: 10.1111/j.1530-0277.2001.tb02333.x

[15] Lucey MR, Mathurin P, Morgan TR. Alcoholic hepatitis. N Engl J Med 2009; 360:2758-2769. doi: 10.1056/NEJMra0805786

[16] Gao B, Bataller R. Alcoholic liver disease: pathogenesis and new therapeutic targets. Gastroenterology 2011;141:1572-1585. doi: 10.1053/j.gastro. 2011.09.002

[17] Mathurin P. Corticosteroids for alcoholic hepatitis-what's next? J Hepatol 2005;43:526-533. doi: 10.1016/j.jhep.2005.06.003

[18] Ramond MJ, Poynard T, Rueff B, Mathurin P, Theodore C, Chaput JC, et al. A randomized trial of prednisolone in patients with severe alcoholic hepatitis. N Engl J Med 1992;326:507-512. doi: 10.1056/NEJM199202203260802

[19] Alexander JF, Lischner MW, Galambos JT. Natural history of alcoholic hepatitis. II. The long-term prognosis. Am J Gastroenterol 1971;56:515-525.

[20] Uchida T, Kao H, Quispe-Sjogren M, Peters RL. Alcoholic foamy degeneration-a pattern of acute alcoholic injury of the liver. Gastroenterology 1983;84: 683-692.

[21] Suri S, Mitros FA, Ahluwalia JP. Alcoholic foamy degeneration and a markedly elevated GGT: a case report and literature review. Dig Dis Sci 2003;48: 1142-1146. doi: 10.1023/A:1023781132498
[22] Piccini J, Haldar S, Jefferson B. Cases from the Osler Medical Service at Johns Hopkins University. Zieve syndrome. Am J Med 2003;115:729-731. doi: 10.1016/j.amjmed.2003.10.005

[23] Amini M, Runyon BA. Alcoholic hepatitis 2010: a clinician's guide to diagnosis and therapy. World J Gastroenterol 2010;16:4905-4912. doi: 10.3748/wjg. v16.i39.4905

[24] Nanji AA, French SW, Mendenhall CL. Serum aspartate aminotransferase to alanine aminotransferase ratio in human and experimental alcoholic liver disease: relationship to histologic changes. Enzyme 1989;41:112-115.

[25] Cohen JA, Kaplan MM. The SGOT/SGPT ratio-an indicator of alcoholic liver disease. Dig Dis Sci 1979;24:835-838. doi: 10.1007/BF01324898

[26] Sohail U, Satapathy SK. Diagnosis and management of alcoholic hepatitis. Clin Liver Dis 2012;16:717-736. doi: 10.1016/j.cld.2012.08.005

[27] Levitsky J, Mailliard ME. Diagnosis and therapy of alcoholic liver disease. Semin Liver Dis 2004;24:233-247. doi: 10.1055/s-2004-832937

[28] Potts JR, Verma S. Alcoholic hepatitis: diagnosis and management in 2012. Expert Rev Gastroenterol Hepatol 2012;6:695-710. doi: 10.1586/egh.12.57

[29] Singal AK, Kamath PS, Gores GJ, Shah VH. Alcoholic hepatitis: current challenges and future directions. Clin Gastroenterol Hepatol 2014;12:555-564; quiz e531-e552.

[30] Altamirano J, Miquel R, Katoonizadeh A, Abraldes JG, Duarte-Rojo A, Louvet A, et al. A histologic scoring system for prognosis of patients with alcoholic hepatitis. Gastroenterology 2014;146:1231-1239. e1231-e1236.

[31] Nguyen-Khac E, Thevenot T, Piquet MA, Benferhat S, Goria O, Chatelain D, et al. Glucocorticoids plus $\mathrm{N}$-acetylcysteine in severe alcoholic hepatitis. $\mathrm{N}$ Engl J Med 2011;365:1781-1789. doi: 10.1056/NEJMoa1101214

[32] Elphick DA, Dube AK, McFarlane E, Jones J, Gleeson D. Spectrum of liver histology in presumed decompensated alcoholic liver disease. Am J Gastroenterol 2007;102:780-788. doi: 10.1111/j.1572-0241.2006.01034.x

[33] Potts JR, Goubet S, Heneghan MA, Verma S. Determinants of long-term outcome in severe alcoholic hepatitis. Aliment Pharmacol Ther 2013;38: 584-595. doi: 10.1111/apt.12427

[34] Mendenhall CL, Anderson S, Weesner RE, Goldberg SJ, Crolic KA. Proteincalorie malnutrition associated with alcoholic hepatitis. Veterans Administration Cooperative Study Group on Alcoholic Hepatitis. Am J Med 1984;76: 211-222. doi: 10.1016/0002-9343(84)90776-9

[35] Mendenhall C, Roselle GA, Gartside P, Moritz T. Relationship of protein calorie malnutrition to alcoholic liver disease: a reexamination of data from two Veterans Administration Cooperative Studies. Alcohol Clin Exp Res 1995; 19:635-641. doi: 10.1111/j.1530-0277.1995.tb01560.x

[36] Diehl AM. Obesity and alcoholic liver disease. Alcohol 2004;34:81-87. doi: 10.1016/j.alcohol.2004.07.010

[37] Henkel AS, Buchman AL. Nutritional support in patients with chronic liver disease. Nat Clin Pract Gastroenterol Hepatol 2006;3:202-209. doi: 10. 1038/ncpgasthep 0443

[38] Cabre E, Rodriguez-Iglesias P, Caballeria J, Quer JC, Sanchez-Lombrana JL, Pares A, et al. Short- and long-term outcome of severe alcohol-induced hepatitis treated with steroids or enteral nutrition: a multicenter randomized trial. Hepatology 2000;32:36-42. doi: 10.1053/jhep.2000.8627

[39] Halsted CH. Nutrition and alcoholic liver disease. Semin Liver Dis 2004;24: 289-304. doi: 10.1055/s-2004-832941

[40] Kearns PJ, Young H, Garcia G, Blaschke T, O'Hanlon G, Rinki M, et al. Accelerated improvement of alcoholic liver disease with enteral nutrition. Gastroenterology 1992;102:200-205.

[41] Griffith CM, Schenker S. The role of nutritional therapy in alcoholic liver disease. Alcohol Res Health 2006;29:296-306.

[42] Singal AK, Charlton MR. Nutrition in alcoholic liver disease. Clin Liver Dis 2012;16:805-826. doi: 10.1016/j.cld.2012.08.009

[43] Mezey E, Potter JJ, Rennie-Tankersley L, Caballeria J, Pares A. A randomized placebo controlled trial of vitamin $\mathrm{E}$ for alcoholic hepatitis. J Hepatol 2004; 40:40-46. doi: 10.1016/S0168-8278(03)00476-8

[44] Dunn W, Jamil LH, Brown LS, Wiesner RH, Kim WR, Menon KV, et al. MELD accurately predicts mortality in patients with alcoholic hepatitis. Hepatology 2005;41:353-358. doi: 10.1002/hep.20503

[45] Mathurin P, O'Grady J, Carithers RL, Phillips M, Louvet A, Mendenhall CL, et al. Corticosteroids improve short-term survival in patients with severe alcoholic hepatitis: meta-analysis of individual patient data. Gut 2011;60:255-260. doi: $10.1136 /$ gut.2010.224097

[46] Taieb J, Mathurin P, Elbim C, Cluzel P, Arce-Vicioso M, Bernard B, et al. Blood neutrophil functions and cytokine release in severe alcoholic hepatitis: effect of corticosteroids. J Hepatol 2000;32:579-586. doi: 10.1016/ S0168-8278(00)80219-6

[47] Mathurin P, Mendenhall CL, Carithers RL Jr, Ramond MJ, Maddrey WC, Garstide $\mathrm{P}$, et al. Corticosteroids improve short-term survival in patients with severe alcoholic hepatitis (AH): individual data analysis of the last three randomized placebo controlled double blind trials of corticosteroids in severe AH. J Hepatol 2002;36:480-487. doi: 10.1016/S0168-8278(01) 00289-6

[48] Carithers RL Jr, Herlong HF, Diehl AM, Shaw EW, Combes B, Fallon HJ, et al. Methylprednisolone therapy in patients with severe alcoholic hepatitis. 
A randomized multicenter trial. Ann Intern Med 1989;110:685-690. doi: 10.7326/0003-4819-110-9-685

[49] Imperiale TF, McCullough AJ. Do corticosteroids reduce mortality from alcoholic hepatitis? A meta-analysis of the randomized trials. Ann Intern Med 1990;113:299-307. doi: 10.7326/0003-4819-113-4-299

[50] Theodossi A, Eddleston AL, Williams R. Controlled trial of methylprednisolone therapy in severe acute alcoholic hepatitis. Gut 1982;23:75-79. doi: 10.1136/gut.23.1.75

[51] Depew W, Boyer T, Omata M, Redeker A, Reynolds T. Double-blind controlled trial of prednisolone therapy in patients with severe acute alcoholic hepatitis and spontaneous encephalopathy. Gastroenterology 1980;78:524-529.

[52] Daures JP, Peray P, Bories P, Blanc P, Yousfi A, Michel H, et al. Corticoid therapy in the treatment of acute alcoholic hepatitis. Results of a metaanalysis. Gastroenterol Clin Biol 1991;15:223-228.

[53] Rambaldi A, Saconato HH, Christensen E, Thorlund K, Wetterslev J, Gluud C. Systematic review: glucocorticosteroids for alcoholic hepatitis-a Cochrane Hepato-Biliary Group systematic review with meta-analyses and trial sequential analyses of randomized clinical trials. Aliment Pharmacol Ther 2008;27:1167-1178. doi: 10.1111/j.1365-2036.2008.03685.x

[54] Singal AK, Walia I, Singal A, Soloway RD. Corticosteroids and pentoxifylline for the treatment of alcoholic hepatitis: Current status. World J Hepatol 2011;3:205-210. doi: 10.4254/wjh.v3.i8.205

[55] Gustot T, Maillart E, Bocci M, Surin R, Trepo E, Degre D, et al. Invasive aspergillosis in patients with severe alcoholic hepatitis. J Hepatol 2014; 60:267-274. doi: 10.1016/j.jhep.2013.09.011

[56] Louvet A, Wartel F, Castel H, Dharancy S, Hollebecque A, Canva-Delcambre V, et al. Infection in patients with severe alcoholic hepatitis treated with steroids: early response to therapy is the key factor. Gastroenterology 2009; 137:541-548. doi: 10.1053/j.gastro.2009.04.062

[57] McCullough AJ, O'Connor JF. Alcoholic liver disease: proposed recommendations for the American College of Gastroenterology. Am J Gastroenterol 1998;93:2022-2036. doi: 10.1111/j.1572-0241.1998.00587.x

[58] Louvet A, Naveau S, Abdelnour M, Ramond MJ, Diaz E, Fartoux L, et al. The Lille model: a new tool for therapeutic strategy in patients with severe alcoholic hepatitis treated with steroids. Hepatology $2007 ; 45: 1348-1354$. doi: 10.1002/hep. 21607

[59] Lechner AJ, Rouben LR, Potthoff LH, Tredway TL, Matuschak GM. Effects of pentoxifylline on tumor necrosis factor production and survival during lethal E. coli sepsis vs. disseminated candidiasis with fungal septic shock. Circ Shock 1993;39:306-315.

[60] McHutchison JG, Runyon BA, Draguesku JO, Cominelli F, Person JL, Castracane J. Pentoxifylline may prevent renal impairment (hepatorenal syndrome) in severe acute alcoholic hepatitis. Hepatology 1991;14:195. Abstract

[61] Assimakopoulos SF, Thomopoulos KC, Labropoulou-Karatza C. Pentoxifylline: a first line treatment option for severe alcoholic hepatitis and hepatorenal syndrome? World J Gastroenterol 2009;15:3194-3195. doi: 10. 3748/wjg.15.3194

[62] Akriviadis E, Botla R, Briggs W, Han S, Reynolds T, Shakil O. Pentoxifylline improves short-term survival in severe acute alcoholic hepatitis: a doubleblind, placebo-controlled trial. Gastroenterology 2000;119:1637-1648. doi: 10.1053/gast.2000.20189

[63] Parker R, Armstrong MJ, Corbett C, Rowe IA, Houlihan DD. Systematic review: pentoxifylline for the treatment of severe alcoholic hepatitis. Aliment Pharmacol Ther 2013;37:845-854. doi: 10.1111/apt.12279

[64] Whitfield K, Rambaldi A, Wetterslev J, Gluud C. Pentoxifylline for alcoholic hepatitis. Cochrane Database Syst Rev 2009:CD007339. doi: 10.1002/ 14651858.cd007339.pub2

[65] Lebrec D, Thabut D, Oberti F, Perarnau JM, Condat B, Barraud H, et al. Pentoxifylline does not decrease short-term mortality but does reduce complications in patients with advanced cirrhosis. Gastroenterology 2010;138: 1755-1762. doi: 10.1053/j.gastro.2010.01.040

[66] Sidhu SS, Goyal O, Singla P, Gupta D, Sood A, Chhina RS, et al. Corticosteroid plus pentoxifylline is not better than corticosteroid alone for improving survival in severe alcoholic hepatitis (COPE trial). Dig Dis Sci 2012;57: 1664-1671. doi: 10.1007/s10620-012-2097-4

[67] Paladugu HS DP, Kudalkar L. Role of pentoxifylline in treatment of severe acute alcoholic hepatitis - a randomized controlled trial. J Gastrentero Hepatol 2006;21:A459.

[68] Thursz MR, Richardson P, Allison M, Austin A, Bowers M, Day CP, et al. Prednisolone or pentoxifylline for alcoholic hepatitis. N Engl J Med 2015; 372:1619-1628. doi: 10.1056/NEJMoa1412278

[69] De BK, Gangopadhyay S, Dutta D, Baksi SD, Pani A, Ghosh P. Pentoxifylline versus prednisolone for severe alcoholic hepatitis: a randomized controlled trial. World J Gastroenterol 2009;15:1613-1619. doi: 10.3748/wjg.15. 1613

[70] Garrido García JR, Sánchez Her- nández G, Melchor López A, Elizalde Barrera CI, Sánchez Vargas L. Pentoxifilina versus esteroide en la sobrevivencia a corto plazo en hepatitis aguda alcohólica severa. Med Int Mex 2012;28:227-233.
[71] Kim DJ, Suk KT, Park SH, Lee HJ, Asg K. Short-term survival in patients with severe alcoholic hepatitis treated with corticosteroid vs. pentoxifylline: a non-inferiority trial. 2011;S33-S34. Available at: http://210.101.116. 28/W_files/kiss8/27404945_pv.pdf.

[72] Park SH, Kim DJ, Kim YS, Yim HJ, Tak WY, Lee HJ, et al. Pentoxifylline vs. corticosteroid to treat severe alcoholic hepatitis: a randomised, noninferiority, open trial. J Hepatol 2014;61:792-798. doi: 10.1016/j.jhep. 2014.05.014

[73] Louvet A. Prednisolone vs. pentoxifylline for severe alcoholic hepatitis. J Hepatol 2014;61:723-724. doi: 10.1016/j.jhep.2014.07.001

[74] Forrest E, Mellor J, Stanton L, Bowers M, Ryder P, Austin A, et al. Steroids or pentoxifylline for alcoholic hepatitis (STOPAH): study protocol for a randomised controlled trial. Trials 2013;14:262. doi: 10.1186/1745-6215-14262

[75] Mathurin P, Louvet A, Duhamel A, Nahon P, Carbonell N, Boursier J, et al. Prednisolone with vs without pentoxifylline and survival of patients with severe alcoholic hepatitis: a randomized clinical trial. JAMA 2013;310: 1033-1041. doi: 10.1001/jama.2013.276300

[76] Louvet A, Diaz E, Dharancy S, Coevoet H, Texier F, Thevenot T, et al. Early switch to pentoxifylline in patients with severe alcoholic hepatitis is inefficient in non-responders to corticosteroids. J Hepatol 2008;48:465-470. doi: 10.1016/j.jhep.2007.10.010

[77] Bird GL, Sheron N, Goka AK, Alexander G], Williams RS. Increased plasma tumor necrosis factor in severe alcoholic hepatitis. Ann Intern Med 1990; 112:917-920. doi: 10.7326/0003-4819-112-12-917

[78] Felver ME, Mezey E, McGuire M, Mitchell MC, Herlong HF, Veech GA, et al. Plasma tumor necrosis factor alpha predicts decreased long-term survival in severe alcoholic hepatitis. Alcohol Clin Exp Res 1990;14:255-259. doi: 10. 1111/j.1530-0277.1990.tb00482.x

[79] Boetticher NC, Peine C], Kwo P, Abrams GA, Patel T, Aqel B, et al. A randomized, double-blinded, placebo-controlled multicenter trial of etanercept in the treatment of alcoholic hepatitis. Gastroenterology 2008;135:19531960. doi: $10.1053 /$ j.gastro.2008.08.057

[80] Naveau S, Chollet-Martin S, Dharancy S, Mathurin P, Jouet P, Piquet MA, et al. A double-blind randomized controlled trial of infliximab associated with prednisolone in acute alcoholic hepatitis. Hepatology 2004;39:13901397. doi: 10.1002/hep. 20206

[81] Lake-Bakaar G. Glucocorticoids plus N-acetylcysteine in alcoholic hepatitis. N Engl J Med 2012;366:476-477; author reply 477. doi: 10.1056/ NEJMc1114239

[82] Singal AK, Guturu P, Hmoud B, Kuo YF, Salameh H, Wiesner RH. Evolving frequency and outcomes of liver transplantation based on etiology of liver disease. Transplantation 2013;95:755-760. doi: 10.1097/TP.0b013e3182 $7 \mathrm{afb} 3 \mathrm{a}$

[83] Singal AK, Chaha KS, Rasheed K, Anand BS. Liver transplantation in alcoholic liver disease current status and controversies. World J Gastroenterol 2013;19:5953-5963. doi: 10.3748/wjg.v19.i36.5953

[84] Singal AK, Duchini A. Liver transplantation in acute alcoholic hepatitis: Current status and future development. World J Hepatol 2011;3:215-218. doi: 10.4254 /wjh.v3.i8.215

[85] Neuberger J, Adams D, MacMaster P, Maidment A, Speed M. Assessing priorities for allocation of donor liver grafts: survey of public and clinicians. BMJ 1998;317:172-175. doi: 10.1136/bmj.317.7152.172

[86] Neuberger J. Public and professional attitudes to transplanting alcoholic patients. Liver Transpl 2007;13:S65-S68. doi: 10.1002/It.21337

[87] Neuberger ], Tang H. Relapse after transplantation: European studies. Liver Transpl Surg 1997;3:275-279. doi: 10.1002/It.500030313

[88] Leong J, Im GY. Evaluation and selection of the patient with alcoholic liver disease for liver transplant. Clin Liver Dis 2012;16:851-863.oi.org/10. 1016/j.cld.2012.08.012

[89] Pfitzmann R, Schwenzer J, Rayes N, Seehofer D, Neuhaus R, Nussler NC. Long-term survival and predictors of relapse after orthotopic liver transplantation for alcoholic liver disease. Liver Transpl 2007;13:197-205. doi: $10.1002 /$ It.20934

[90] Rice JP, Lucey MR. Should length of sobriety be a major determinant in liver transplant selection? Curr Opin Organ Transplant 2013;18:259-264. doi: 10.1097/MOT.0b013e32835fb94b

[91] Mathurin P, Moreno C, Samuel D, Dumortier J, Salleron J, Durand F, et al. Early liver transplantation for severe alcoholic hepatitis. N Engl J Med 2011; 365:1790-1800. doi: 10.1056/NEJMoa1105703

[92] Singal AK, Bashar H, Anand BS, Jampana SC, Singal V, Kuo YF. Outcomes after liver transplantation for alcoholic hepatitis are similar to alcoholic cirrhosis: exploratory analysis from the UNOS database. Hepatology 2012;55: 1398-1405. doi: 10.1002/hep.25544

[93] Cuadrado A, Fabrega E, Casafont F, Pons-Romero F. Alcohol recidivism impairs long-term patient survival after orthotopic liver transplantation for alcoholic liver disease. Liver Transpl 2005;11:420-426. doi: 10.1002/It. 20386 
[94] Pageaux GP, Bismuth M, Perney P, Costes V, Jaber S, Possoz P, et al. Alcohol relapse after liver transplantation for alcoholic liver disease: does it matter? J Hepatol 2003;38:629-634. doi: 10.1016/S0168-8278(03)00088-6

[95] Mackie J, Groves K, Hoyle A, Garcia C, Garcia R, Gunson B, et al. Orthotopic liver transplantation for alcoholic liver disease: a retrospective analysis of survival, recidivism, and risk factors predisposing to recidivism. Liver Transpl 2001;7:418-427. doi: 10.1053/jlts.2001.23789

[96] Bertola A, Mathews S, Ki SH, Wang H, Gao B. Mouse model of chronic and binge ethanol feeding (the NIAAA model). Nat Protoc 2013;8:627-637. doi: $10.1038 /$ nprot.2013.032

[97] Szabo G. Gut-liver axis in alcoholic liver disease. Gastroenterology 2015; 148:30-36. doi: 10.1053/j.gastro.2014.10.042

[98] Yan AW, Schnabl B. Bacterial translocation and changes in the intestinal microbiome associated with alcoholic liver disease. World J Hepatol 2012 4:110-118. doi: $10.4254 /$ wjh.v4.i4.110

[99] Loguercio C, Federico A, Tuccillo C, Terracciano F, D'Auria MV, De Simone C, et al. Beneficial effects of a probiotic VSL\#3 on parameters of liver dysfunction in chronic liver diseases. J Clin Gastroenterol 2005;39:540-543. doi: 10.1097/01.mcg.0000165671.25272.0f

[100] Kirpich IA, Solovieva NV, Leikhter SN, Shidakova NA, Lebedeva OV, Sidorov PI, et al. Probiotics restore bowel flora and improve liver enzymes in human alcohol-induced liver injury: a pilot study. Alcohol 2008;42:675-682. doi: 10.1016/j.alcohol.2008.08.006

[101] Louvet A, Mathurin P. Alcoholic liver disease: mechanisms of injury and targeted treatment. Nat Rev Gastroenterol Hepatol 2015;12:231-242. doi: $10.1038 /$ nrgastro.2015.35

[102] Dinarello CA, Simon A, van der Meer JW. Treating inflammation by blocking interleukin-1 in a broad spectrum of diseases. Nat Rev Drug Discov 2012 11:633-652. doi: $10.1038 /$ nrd3800

[103] Petrasek J, Bala S, Csak T, Lippai D, Kodys K, Menashy V, et al. IL-1 receptor antagonist ameliorates inflammasome-dependent alcoholic steatohepatitis in mice. J Clin Invest 2012;122:3476-3489. doi: 10.1172/JCI60777

[104] Ki SH, Park O, Zheng M, Morales-Ibanez O, Kolls JK, Bataller R, et al. Interleukin-22 treatment ameliorates alcoholic liver injury in a murine model of chronic-binge ethanol feeding: role of signal transducer and activator of transcription 3. Hepatology 2010;52:1291-1300. doi: 10.1002/hep. 23837

[105] Natori S, Rust C, Stadheim LM, Srinivasan A, Burgart LJ, Gores G]. Hepatocyte apoptosis is a pathologic feature of human alcoholic hepatitis. J Hepatol 2001;34:248-253. doi: 10.1016/S0168-8278(00)00089-1

[106] Chakraborty JB, Oakley F, Walsh MJ. Mechanisms and biomarkers of apoptosis in liver disease and fibrosis. Int J Hepatol 2012;2012:648915. doi: 10. $1155 / 2012 / 648915$

[107] Ratziu V, Sheikh MY, Sanyal AJ, Lim JK, Conjeevaram H, Chalasani N, et al. A phase 2, randomized, double-blind, placebo-controlled study of GS-9450 in subjects with nonalcoholic steatohepatitis. Hepatology 2012;55:419-428. doi: $10.1002 /$ hep. 24747

[108] Ali AH, Carey EJ, Lindor KD. Recent advances in the development of farnesoid X receptor agonists. Ann Transl Med 2015;3:5.
[109] Hirschfield GM, Mason A, Luketic V, Lindor K, Gordon SC, Mayo M, et al. Efficacy of obeticholic Acid in patients with primary biliary cirrhosis and inadequate response to ursodeoxycholic Acid. Gastroenterology 2015; 148:751-761.e758. doi: 10.1053/j.gastro.2014.12.005

[110] Neuschwander-Tetri BA. Targeting the FXR nuclear receptor to treat liver disease. Gastroenterology 2015;148:704-706. doi: 10.1053/j.gastro. 2015.02.037

[111] Weber SN, Wasmuth HE. Liver fibrosis: from animal models to mapping of human risk variants. Best Pract Res Clin Gastroenterol 2010;24:635-646. doi: $10.1016 /$ j.bpg.2010.07.013

[112] Choi SM, Liu H, Chaudhari P, Kim Y, Cheng L, Feng J, et al. Reprogramming of EBV-immortalized B-lymphocyte cell lines into induced pluripotent stem cells. Blood 2011;118:1801-1805. doi: 10.1182/blood-2011-03-340620

[113] Liu H, Kim Y, Sharkis S, Marchionni L, Jang YY. In vivo liver regeneration potential of human induced pluripotent stem cells from diverse origins. Sci Transl Med 2011;3:82ra39. doi: 10.1126/scitranslmed.3002376

[114] Liu H, Ye Z, Kim Y, Sharkis S, Jang YY. Generation of endoderm-derived human induced pluripotent stem cells from primary hepatocytes. Hepatology 2010;51:1810-1819. doi: 10.1002/hep.23626

[115] Yu J, Vodyanik MA, Smuga-Otto K, Antosiewicz-Bourget J, Frane JL, Tian S, et al. Induced pluripotent stem cell lines derived from human somatic cells. Science 2007;318:1917-1920. doi: 10.1126/science.1151526

[116] Choi SM, Kim Y, Shim JS, Park JT, Wang RH, Leach SD, et al. Efficient drug screening and gene correction for treating liver disease using patientspecific stem cells. Hepatology 2013;57:2458-2468. doi: 10.1002/hep. 26237

[117] Ye Z, Zhan H, Mali P, Dowey S, Williams DM, Jang YY, et al. Human-induced pluripotent stem cells from blood cells of healthy donors and patients with acquired blood disorders. Blood 2009;114:5473-5480. doi: 10.1182/ blood-2009-04-217406

[118] Chaudhari P, Prasad N, Tian L, Jang YY. Determination of Functional Activity of Human iPSC-Derived Hepatocytes by Measurement of CYP Metabolism. Methods Mol Biol 2016;1357:383-394. doi: 10.1007/7651_2014_145

[119] Choi SM, Kim Y, Liu H, Chaudhari P, Ye Z, Jang YY. Liver engraftment potential of hepatic cells derived from patient-specific induced pluripotent stem cells. Cell Cycle 2011;10:2423-2427. doi: 10.4161/cc.10.15.16869

[120] Chun YS, Chaudhari P, Jang YY. Applications of patient-specific induced pluripotent stem cells; focused on disease modeling, drug screening and therapeutic potentials for liver disease. Int J Biol Sci 2010;6:796-805. doi: 10. $7150 /$ ijbs.6.796

[121] Jang YY, Ye Z, Cheng L. Molecular imaging and stem cell research. Mol Imaging 2011;10:111-122.

[122] Sharkis SJ, Jones RJ, Civin C, Jang YY. Pluripotent stem cell-based cancer therapy: promise and challenges. Sci Transl Med 2012;4:127ps129. doi: 10.1126/scitransImed. 3003920

[123] Tian L, Prasad N, Jang YY. In Vitro Modeling of Alcohol-Induced Liver Injury Using Human-Induced Pluripotent Stem Cells. Methods Mol Biol 2016; 1353:271-283. doi: 10.1007/7651_2014_168 